\title{
Socio-economic determinants of selected dietary indicators in British pre-school children
}

\author{
Richard G Watt*, Joanna Dykes and Aubrey Sheiham \\ Department of Epidemiology and Public Health, Royal Free Hospital and University College London Medical School, \\ University College London, London WC1E 6BT, UK
}

Submitted 2 November 1999: Accepted 30 May 2001

\begin{abstract}
Objectives: To assess the proportion of pre-school children meeting reference nutrient intakes (RNIs) and recommendations for daily intakes of iron, zinc, vitamins $\mathrm{C}$ and $\mathrm{A}$, and energy from non-milk extrinsic sugars. To assess whether meeting these five dietary requirements was related to a series of socio-economic variables. Design: Secondary analysis of data on daily consumption of foods and drinks from the National Diet and Nutrition Survey (NDNS) of children aged 1.5-4.5 years based on 4-day weighed intakes.

Subjects: One thousand six hundred and seventy-five British pre-school children aged $1.5-4.5$ years in 1993 .

Results: Only 1\% of children met all five RNIs/recommendations examined; $76 \%$ met only two or fewer. Very few children met the recommendations for intakes of zinc (aged over four years) and non-milk extrinsic sugars (all ages). The number of RNIs/ recommendations met was related to measures of socio-economic class. Children from families in Scotland and the North of England, who had a manual head of household and whose mothers had fewest qualifications, met the least number of RNIs/recommendations.

Conclusions: Very few pre-school children have diets that meet all the RNIs and recommendations for iron, zinc, vitamins $\mathrm{C}$ and $\mathrm{A}$, and energy from non-milk extrinsic sugars. Dietary adequacy with respect to these five parameters is related to socio-economic factors. The findings emphasise the need for a range of public health policies that focus upon the social and economic determinants of food choice within families.
\end{abstract}

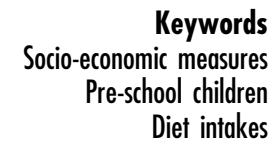

Nutrition influences both the current and the future health of the child. Pre-school children are especially vulnerable to the effects of poor nutrition on their physical and cognitive development.

Iron deficiency is a commonly reported dietary deficiency in British pre-school children ${ }^{1}$. Amongst certain minority ethnic groups up to $34 \%$ of otherwise healthy children under five may have levels of haemoglobin consistent with iron deficiency ${ }^{2}$. Other vitamins and minerals of particular relevance to this age group include zinc, and vitamins A and C. Significant numbers of children have diets that do not regularly provide adequate intakes of these vitamins and minerals ${ }^{3,4}$. In addition, consumption of non-milk extrinsic sugars (NMES) is an area of concern since it frequently exceeds the Department of Health's recommended limit of $10 \%$ of total daily energy. Frequency of NMES intake (which correlates strongly with amount of NMES consumed) is associated with dental caries 5 .
Social gradients exist in nutrition as in many other areas of health and health behaviour ${ }^{6}$. Lower-income households spend a greater proportion of their disposable income on food than more affluent households ${ }^{7}$ but have lower intakes of fruit and vegetables ${ }^{8}$ and consequently lower levels of vitamin $\mathrm{C}$ and carotene?. Children in deprived areas are also more likely to have a diet high in sugars and saturated fat and lower intakes of a number of vitamins and minerals ${ }^{10}$.

The types of food adults choose for themselves and for their children are influenced by more than personal taste, attitudes and nutritional knowledge. The role of individual factors needs to be viewed within the structural and economic framework of food access and cost. The increase of out-of-town supermarkets and the decline in local markets and shops have made car ownership an important factor in regular access to a range of affordable foods ${ }^{11,12}$ and have affected low-income families' ability to shop and plan meals. Therefore having a low income 
Table 1 Percentage of children meeting RNIs/Department of Health recommendations for the five dietary indicators

\begin{tabular}{|c|c|c|c|}
\hline $\begin{array}{l}\text { RNI or recommended } \\
\text { intake }\end{array}$ & $\begin{array}{l}\% \text { meeting } \mathrm{RNI} \text { or } \\
\text { recommendation }\end{array}$ & $\begin{array}{l}\text { Mean daily intake } \\
\text { (standard deviation) }\end{array}$ & $\begin{array}{l}95 \% \text { confidence } \\
\text { interval for mean }\end{array}$ \\
\hline \multicolumn{4}{|l|}{ Iron } \\
\hline $1-3$ years: $6.9 \mathrm{mg}$ day $^{-1}$ & 15.9 & $5.46 \mathrm{mg}(2.36)$ & $5.34,5.57$ \\
\hline $4-6$ years: $6.1 \mathrm{mg}$ day $^{-1}$ & 42.7 & $6.10 \mathrm{mg}(2.61)$ & $5.76,6.43$ \\
\hline \multicolumn{4}{|l|}{ Zinc } \\
\hline $1-3$ years: $5.0 \mathrm{mg} \mathrm{day}^{-1}$ & 27.7 & $4.37 \mathrm{mg}(1.41)$ & $4.31,4.42$ \\
\hline $4-6$ years: $6.5 \mathrm{mg}$ day $^{-1}$ & 10.6 & $4.62 \mathrm{mg}(1.47)$ & $4.44,4.79$ \\
\hline \multicolumn{4}{|l|}{ Vitamin A } \\
\hline $1-6$ years: $400 \mathrm{mg}$ day $^{-1}$ & 55.6 & 578 mg (860.61) & $536.78,619.21$ \\
\hline \multicolumn{4}{|l|}{ Vitamin C } \\
\hline $1-6$ years: $30 \mathrm{mg} \mathrm{day}^{-1}$ & 64.8 & $51.75 \mathrm{mg}(42.35)$ & $49.73,53.76$ \\
\hline \multicolumn{4}{|l|}{$\%$ Energy from non-milk extrinsic sugars } \\
\hline Not $>10 \%$ energy & 12.5 & $18.72 \%$ energy $(7.74)$ & $18.36,19.07$ \\
\hline
\end{tabular}

affects the nutritional status of family members, including young children.

Previous studies of children's diets have tended to look at individual micronutrient intakes and social class. Few have examined dietary adequacy, in terms of reference nutrient intakes (RNIs), across a range of vitamin, mineral and micronutrient intakes. The aim of this study was to look at five key dietary parameters for children in the 1.54.5-year age group and relate dietary adequacy to a variety of socio-economic measures.

\section{Method}

Data used for the study were taken from the National Diet and Nutrition Survey of children aged $1.5-4.5$ years $^{3}$. One thousand six hundred and seventy-five families with preschool children completed 4-day weighed dietary diaries for at least one child. They also participated in face-toface interviews that recorded a wide range of social, demographic and economic details, as well as information related to the child's eating habits and general health.

Secondary analysis of the data was undertaken to construct a composite variable from information on key dietary parameters. This was examined for associations with a variety of socio-economic measures, using chisquare tests and logistic regression.

\section{Results}

Table 1 shows the distribution of the sample of 1675 children aged 1.5-4.5 years across the five dietary parameters considered individually. Of the five parameters examined, the greatest proportion of children met the RNI for vitamin C (64.8\%) and vitamin A (55.6\%). However, only $10.6 \%$ and $15.9 \%$ of $1-3$ year olds reached the RNI for zinc and iron, respectively. Only $12.5 \%$ of the whole sample had NMES intakes within the recommended levels.

Table 2 gives the proportion of children meeting none to all five of the dietary parameters. Only $9.8 \%$ of the sample reached the RNIs/recommendations for four or more of the parameters and only $1 \%$ met all five. A substantial number of children (15.6\%) met none of the five parameters.

The scores on the five dietary indicators were collapsed to three groups: children meeting one or none, children meeting two or three, and children meeting four or five. These scores were analysed using chi-square tests and were found to be related to a number of family socioeconomic variables, most notably in the distributions for those children reaching one or none of the chosen indicators (Table 3). A clear social gradient emerged for the majority of the socio-economic variables examined. Significantly higher proportions of children only reaching one or none of the RNIs/recommendations were in households which:

- were renting their accommodation;

- had received income support in the last fortnight;

- had unemployed heads of household;

- had heads of households whose current or most recent occupation was manual;

- had no car;

- had lower levels of maternal education;

- were located in Scotland and the North of England; and

- had gross household incomes less than $£ 25000$ per annum.

Scores did not vary significantly by sex of the child and age group (1.5-2.5 years compared with $2.5-3.5$ years and $3.5-4.5$ years).

Table 2 Frequency distribution of scores across the five dietary indicators

\begin{tabular}{lcc}
\hline $\begin{array}{l}\text { Number of RNIs or } \\
\text { recommendations met }\end{array}$ & \% of sample $(n)$ & Cumulative \% \\
\hline 0 & $15.6(261)$ & 15.6 \\
1 & $28.8(482)$ & 44.4 \\
2 & $28.6(479)$ & 73.0 \\
3 & $17.3(289)$ & 90.3 \\
4 & $8.8(148)$ & 99.1 \\
5 & $1.0(16)$ & 100 \\
& Base $=1675$ & \\
\hline
\end{tabular}


Table 3 Socio-economic variables and scores across the five dietary parameters

\begin{tabular}{|c|c|c|c|}
\hline Socio-economic indicator & Groups compared & $\begin{array}{l}\% \text { meeting one or none of } \\
\text { the five dietary parameters }\end{array}$ & $P$-value \\
\hline \multirow[t]{4}{*}{ Accommodation } & Rented (HA/LA)* & 55 & \\
\hline & Owner occupied & 40 & \\
\hline & Rented (private) & 40 & \\
\hline & Free accommodation & 33 & $P<0.00001$ \\
\hline \multirow[t]{2}{*}{ Car ownership } & No car & 54 & \\
\hline & Car owner & 41 & $P<0.00001$ \\
\hline \multirow[t]{7}{*}{ Gross household income per annum } & $£ 0-3999$ & 46 & \\
\hline & $£ 4000-5999$ & 59 & \\
\hline & $£ 6000-9999$ & 46 & \\
\hline & $£ 10000-13999$ & 49 & \\
\hline & $£ 14000-17999$ & 44 & \\
\hline & $£ 18000-24999$ & 43 & $P<0.001$ \\
\hline & $£ 25000+$ & 29 & \\
\hline \multirow[t]{2}{*}{ Income support } & Drawn in last fortnight & 51 & \\
\hline & Not drawn in last fortnight & 42 & $P<0.0001$ \\
\hline \multirow[t]{3}{*}{ Employment } & Household head unemployed & 51 & \\
\hline & Household head economically inactive & 48 & \\
\hline & Household head working & 42 & $P<0.01$ \\
\hline \multirow[t]{2}{*}{ Occupation } & Manual & 51 & \\
\hline & Non-manual & 36 & $P<0.00001$ \\
\hline \multirow[t]{2}{*}{ Family } & Married or cohabiting couple & 44 & \\
\hline & Lone parent & 44 & NS \\
\hline \multirow[t]{4}{*}{ Mother's education } & No formal qualifications & 53 & \\
\hline & CSE/GCSE/O levels & 48 & \\
\hline & A levels & 36 & \\
\hline & Degree & 28 & $P<0.00001$ \\
\hline \multirow[t]{4}{*}{ Region } & Scotland & 54 & \\
\hline & North England & 49 & \\
\hline & Central/South West England & 44 & \\
\hline & London and South East & 38 & $P<0.001$ \\
\hline
\end{tabular}

* $\mathrm{HA}=$ Housing Association; LA = local authority.

$\mathrm{NS}=$ not significant

In order to assess the relative effects of each of the above socio-economic variables in predicting which children met one or none of the RNIs/recommendations or a greater number, a logistic regression was undertaken. The results are presented in Table 4 .

The variables that were significant independent predictors of reaching only one or fewer of the five RNIs/ recommendations were:

- a head of household with a (current or most recent) manual occupation;

- a mother with lower qualifications than A levels; and

- living outside London and the South East region.

Together these variables accounted for $60 \%$ of the variance. Maternal education showed the highest odds ratio. Children whose mothers had no qualifications were 2.25 times more likely to reach one or fewer RNIs/ recommendations than those whose mothers had degree level education. Children living in Scotland were almost twice as likely to meet one or none indicators as those living in London and the South East region. To illustrate this further these three variables were considered together. Seventy-nine per cent of children with 'optimum' backgrounds (non-manual occupation, mother with A levels or degree level education, living in London and the South East) met more than one RNI/recommendation compared with 50\% of those from manual, lower maternal education families living outside London and the South East.

\section{Discussion}

The study was based on the data from the National Diet and Nutrition Survey and provides a large, regionally and socio-economically representative picture of diet and nutrition in British pre-school children. The measures of nutrient intake were based on data from 4-day dietary diaries. This method of data collection was chosen by the NDNS researchers as the optimum form of measurement for both data quality and high completion rates ${ }^{1}$.

The results suggest that very few pre-school children in the UK have diets that are fully adequate in terms of the key dietary indicators examined. Only 1\% of children met all five RNIs/recommendations and $15.6 \%$ met none.

Fewest children aged over 4 years reached the RNI for zinc (10.6\%). Pre-school children's intakes of zinc have received less attention than iron intakes but are an area for concern. The initial report on the NDNS found that $14 \%$ of children under four years and $37 \%$ over four had zinc intakes below even the lower reference nutrient intake (LRNI) ${ }^{3}$. Iron intakes remained a problem for the youngest children, with $15.9 \%$ of $1-3$ year olds failing to 
Table 4 Logistic regression model for meeting one or fewer RNIs/recommendations by a range of socio-economic measures

\begin{tabular}{|c|c|c|c|c|}
\hline Variable & $n$ & OR $(95 \% \mathrm{Cl})^{*}$ & $P$-value & $\begin{array}{l}\% \text { of cases correctly } \\
\text { predicted by total model }\end{array}$ \\
\hline \multicolumn{5}{|c|}{ Occupational class vs. non-manual $(n=818)$} \\
\hline Manual & 972 & $1.45(1.21-1.69)$ & 0.002 & 60.09 \\
\hline \multicolumn{5}{|c|}{ Mother's highest qualification vs. degree $(n=329)$} \\
\hline None & 423 & $2.25(1.85-2.65)$ & 0.0001 & \\
\hline CSE & 273 & $2.17(1.75-2.58)$ & 0.0002 & \\
\hline O level & 630 & $1.93(1.59-2.26)$ & 0.0001 & \\
\hline A level & 200 & $1.44(1.02-1.86)$ & NS & \\
\hline \multicolumn{5}{|c|}{ Region vs. LASER $+(n=577)$} \\
\hline Scotland & 188 & $1.99(1.58-2.40)$ & 0.001 & \\
\hline North & 466 & $1.52(1.23-1.82)$ & 0.004 & \\
\hline Central, SW \& Wales & 628 & $1.15(0.88-1.43)$ & NS & \\
\hline
\end{tabular}

* Odds ratio (95\% confidence interval).

† LASER $=$ London and South East region.

NS $=$ not significant.

meet the RNI for iron. It is likely that both iron and zinc intakes are interrelated and reflect reductions in the consumption of meat products and green vegetables.

Only $12.5 \%$ of children had intakes of non-milk extrinsic sugars within recommended limits. Sugary foods and drinks are becoming a substantial part of the diet of young children and pose a threat to their dental health ${ }^{13}$.

Over half the sample met the RNIs for vitamins C and A, with - in some cases - intakes that exceeded the RNI several times over. Although intakes are still below optimum levels for some children, these vitamins appear to be easier to obtain through food/drink or supplementary sources than iron and zinc.

The current RNIs and dietary recommendations may be higher than is necessary for this age group. For example, interpolation from the adult RNI for zinc to derive estimates for children has been described as 'generous' in the report on dietary reference values from the Committee for Medical Aspects of Food Policy $(\mathrm{COMA})^{14}$. The same report also points to studies showing satisfactory plasma retinol levels in pre-school children with lower intakes than the RNI for vitamin A. However, in general, the data in this study suggest wide variations in intakes of non-milk extrinsic sugars and the vitamins and minerals studied. It is therefore likely that a number of children have diets that would fail to meet even quite considerably lowered recommendations.

Meeting one or none RNIs/recommendations was related to socio-economic measures, most notably mother's education, region and social class of head of household. Social gradients based on socio-economic class and region have been found in studies of adult nutrition but less is known about the role of education independent of these and other socio-economic factors. The findings from this study indicate that, for young children, maternal education may be the most important factor determining the five aspects of diet examined.

A comprehensive range of strategies is required to improve the quality of young children's diets ${ }^{15}$. The social and economic determinants of food choice within families need to be addressed. Effective action will only be secured through developing partnerships between the different agencies and sectors that can have an impact on costs, availability and appeal of healthier foods and drinks for young children. In addition, a range of social policies needs to be developed to support families with young children.

\section{Acknowledgements}

The authors would like to thank the University of Essex Data Archive for providing the NDNS data files and the assistance of NDNS researchers at MAFF for kindly providing further information on the data set. We are also grateful to Drs Pauline McGlone, Mel Bartley and Eric Brunner for their helpful comments on this paper. No external funding was received to support this study.

\section{References}

1 Sherriff A, Emond A, Hawkins N, Golding J. Haemoglobin and ferritin concentrations in children aged 12 and 18 months. Arch. Dis. Child 1999; 80: 153-7.

2 Duggan MB, Harbottle L, Noble C. The weaning diet of healthy Asian children living in Sheffield. 1. The level and composition of the diet in children from 4-40 months of age. J. Hum. Nutr. Diet. 1992; 5: 189-200.

3 Gregory JR, Collins DL, Davies PSW, Hughes JM, Clarke PC. National Diet and Nutrition Survey: Children aged 15 to 45 years. Volume 1. Report of the Diet and Nutrition Survey. London: HMSO, 1995.

4 Caroline Walker Trust. Eating Well for the Under-5s in Childcare. London: Caroline Walker Trust, 1998.

5 Department of Health. Dietary Sugars and Human Disease. COMA Report on Health and Social Subjects No. 37. London: HMSO, 1989.

6 Independent Inquiry into Inequalities in Health Report. London: Stationery Office, 1998.

7 Leather S. The Making of Modern Malnutrition: An Overview of Food Poverty in the UK. The Caroline Walker Lecture. London: Caroline Walker Trust, 1996.

8 Leather S. Fruit and vegetables: consumption patterns and health consequences. Br. Food J. 1995; 97: 7. 
9 Lobstein T. The Nutrition of Women on Low Incomes. London: The Food Commission, 1991.

10 Doyle W, et al. Nutritional survey of schoolchildren in an inner city area. Arch. Dis. Child. 1994; 70: 376-81.

11 Philip W, James T, Nelson M, Ralph A, Leather S. The contribution of nutrition to inequalities in health. BMJ 1997; 314: 1545-9.

12 Lang T, Caraher M. Access to healthy foods: part II. Food poverty and shopping deserts: what are the implications for health promotion policy and practice. Health. Educ. J. 1998; 57: $202-11$.
13 Watt RG, Dykes J, Sheiham A. Pre-school children's consumption of drinks: implications for dental health. Community Dent. Health 2001; 17: 8-13.

14 Department of Health. Dietary Reference Values for Food Energy and Nutrients for the United Kingdom. COMA Report on Health and Social Subjects No. 41. London: HMSO, 1991.

15 Stockley L. Summary of the Promotion of Healthier Eating: A Basis for Action. London: Health Education Authority, 1993. 